\title{
Device Emits Odor
}

National Cancer Institute

\section{Source}

National Cancer Institute. Device Emits Odor. NCI Thesaurus. Code C63004.

Problem associated with an unexpected or inappropriate smell released by the device. 